\title{
Efficient Helium Separation with Two-Dimensional Metal-Organic Framework Fe/Ni-PTC: A Theoretical Study
}

\author{
Jingyuan Wang ${ }^{1}$, Yixiang $\mathrm{Li}^{1}{ }^{1}$, Yanmei Yang ${ }^{2}$, Yongqiang $\mathrm{Li}^{1}{ }^{1}$, Mingwen Zhao ${ }^{1} \mathbb{(}$, Weifeng $\mathrm{Li}^{1}{ }^{1}$, Jing Guan ${ }^{1, *}$ \\ and Yuanyuan $Q \mathbf{u}^{1, *(D)}$ \\ 1 School of Physics, Shandong University, Jinan 250100, China; wjy96@mail.sdu.edu.cn (J.W.); \\ lyx1113@mail.sdu.edu.cn (Y.L.); yqli@sdu.edu.cn (Y.L.); zmw@sdu.edu.cn (M.Z.); lwf@sdu.edu.cn (W.L.) \\ 2 College of Chemistry, Chemical Engineering and Materials Science, Shandong Normal University, \\ Jinan 250014, China; yym@sdnu.edu.cn \\ * Correspondence: guanjing@sdu.edu.cn (J.G.); quyuanyuan@sdu.edu.cn (Y.Q.)
}

check for updates

Citation: Wang, J.; Li, Y.; Yang, Y.; Li, Y.; Zhao, M.; Li, W.; Guan, J.; Qu, Y. Efficient Helium Separation with Two-Dimensional

Metal-Organic Framework Fe/Ni-PTC: A Theoretical Study. Membranes 2021, 11, 927.

https://doi.org/10.3390/

membranes11120927

Academic Editor: Beatriz Zornoza

Received: 1 November 2021

Accepted: 23 November 2021

Published: 26 November 2021

Publisher's Note: MDPI stays neutral with regard to jurisdictional claims in published maps and institutional affiliations.

Copyright: (c) 2021 by the authors. Licensee MDPI, Basel, Switzerland. This article is an open access article distributed under the terms and conditions of the Creative Commons Attribution (CC BY) license (https:/ / creativecommons.org/licenses/by/ $4.0 /)$.

\begin{abstract}
Helium ( $\mathrm{He}$ ) is one of the indispensable and rare strategic materials for national defense and high-tech industries. However, daunting challenges have to be overcome for the supply shortage of He resources. Benefitted from the wide pore size distribution, sufficient intrinsic porosity, and high specific surface area, metal-organic framework (MOF) materials are prospective candidates for He purification in the membrane-based separation technology. In this work, through first-principles calculations and molecular dynamics (MD) simulations, we studied the permeability and filtration performance of He by the newly synthesized two-dimensional Fe-PTC MOF and its analogue Ni-PTC MOF. We found that both Fe-PTC and Ni-PTC have superior high performance for He separation. The selectivity of He over $\mathrm{N}_{2}$ was calculated to be $\sim 10^{17}$ for Fe-PTC and $\sim 10^{15}$ for Ni-PTC, respectively, both higher than most of the previously proposed 2D porous membranes. Meanwhile, high He permeance $\left(10^{-4} \sim 10^{-3} \mathrm{~mol} \mathrm{~s}^{-1} \mathrm{~m}^{-2} \mathrm{~Pa}^{-1}\right)$ can be obtained for the Fe/Ni-PTC MOF for temperatures ranging from 200 to $500 \mathrm{~K}$. Therefore, the present study offers a highly prospective membrane for $\mathrm{He}$ separation, which has great potential in industrial application.
\end{abstract}

Keywords: gas separation; metal-organic framework; membrane-based separation; molecular dynamics simulation; first-principles calculations

\section{Introduction}

As a rare strategic material, helium $(\mathrm{He})$ is urgently needed in the medical, scientific research, and aerospace industries [1-3]. Albeit being the second most abundant element in the universe, He is still scarce in the atmosphere. Currently, the main source of He is the by-product in the exploitation of natural gas [4,5]. Purification of He with membranebased separation technology has become a promising method, because of its low energy consumption, eco-friendly nature, simple operation, and other advantages [6-10].

The recent quick advances in the development of nanoporous two-dimensional (2D) structures have provided superior membrane candidates for He separation, in the merit of their intrinsic porosity, atomic thickness, and high specific surface area. For instance, graphene [9], silicene [11], and $\mathrm{MoS}_{2}$ [12] with drilling holes have been proposed for He separation and demonstrated to be successful. However, the requirement of precise treatment to these materials to introduce properly-sized hole structure becomes a technique hindrance, thus 2D structures with intrinsically distributed nanopores have attracted more attention which are highly expected to be efficient filtration membranes. For example, in 2015, the experimentally available $\mathrm{g}-\mathrm{C}_{3} \mathrm{~N}_{4}$ membrane has been demonstrated to possess high selectivity $\left(10^{7} \sim 10^{65}\right.$ at $\left.300 \mathrm{~K}\right)$ for separating He from impure gas molecules $\left(\mathrm{H}_{2}, \mathrm{~N}_{2}\right.$, $\mathrm{CO}, \mathrm{CH}_{4}, \mathrm{Ne}$, and Ar) in natural gas [13]. Then, Wang et al. theoretically predicted high He selectivity $\left(10^{2} \sim 10^{38}\right.$ at $\left.300 \mathrm{~K}\right)$ and permeance $\left(1.0 \times 10^{3} \mathrm{GPU}\right)$ of the monolayer CTF-0 membrane for He treatment [14]. Very recently, Liu et al. has shown that the nano-porous 
g- $\mathrm{C}_{2} \mathrm{O}$ membrane is a promising membrane for He separation with high selectivity (30 10 28 at $300 \mathrm{~K})$ and permeance $\left(1.03 \times 10^{7} \mathrm{GPU}\right)$ [15]. In addition, other intrinsically porous $2 \mathrm{D}$ materials, including $\mathrm{C}_{2} \mathrm{~N}$ [16], IGP [17] and graphenylenee-1 [18], have also shown good performance for He separation. It should be noted that the trade-off between the selectivity and permeance is inherent in the system with porous structure, as large pores are favored by high permeance and small pores are advantageous to the selectivity of small molecules like He. Therefore, searching for a membrane with properly-sized pores for He separation is of great importance to achieve the goal of optimized balance of high permeance with sufficiently high selectivity.

Metal-organic frameworks (MOFs) are a new class of nanoporous materials, which is constituted of metal nodes connected by organic linkers $[19,20]$. Due to the high diversity of functional groups and ligands, the structure of MOFs can be tailored during the synthesis process, resulting in a large variety of structures with diverse geometries, pore sizes, and functional groups [21]. To date, a great deal of MOFs has been reported with excellent properties, such as high pore volume, large surface area, wide range of pore size from micro to meso scale, and reasonable thermal and mechanical stability. Based on these properties, application studies of MOFs for gas storage and separation [22-26], drug delivery [27], and catalysis $[25,28]$ are widely explored. In particular, because of the rich porous structure, many MOFs have been proposed to be effective membrane materials in gas separation. Ranjan et al. [29] showed that microporous metal-organic framework (MMOF) membranes exhibit industrially acceptable selectivity of 23 for $\mathrm{H}_{2} / \mathrm{N}_{2}$ separation at $363 \mathrm{~K}$. Cao et al. [30] demonstrated that the $\mathrm{Cu}-\mathrm{BTC}$ membrane can be used for He separation with moderate selectivities and permeance for He over $\mathrm{CO}_{2}, \mathrm{~N}_{2}$, and $\mathrm{CH}_{4}$, comparable to previously reported MOF membranes. In 2018, a highly crystalline ZIF-68 membrane was synthesized by Kasik et al., which offered a high He permeance of $2.6 \times 10^{-7} \mathrm{~mol} \mathrm{~s}^{-1} \mathrm{~m}^{-2} \mathrm{~Pa}^{-1}$ [31]. The above-mentioned reports are all based on three-dimensional (3D) MOF structures, and relative application studies of 2D MOFs in gas separation are rare.

In 2018, Dong et al. successfully synthesized the black polycrystalline 2D Fe-PTC MOF by solvothermal method, which exhibits a high electrical conductivity of $10 \mathrm{~S} \mathrm{~cm}^{-1}(300 \mathrm{~K})$ and a ferromagnetism $(<20 \mathrm{~K})$, implying its potential as a ferromagnetic semiconductor for application in spintronics [32]. It is noticed that the pore size of the Fe-PTC MOF is about $5.65 \AA$ [33], similar to that of IGP (5.47 $\AA$ ) [17] which has good performance on He separation. In addition, by replacing the transition metal atoms in the Fe-PTC MOF, a group of analogues can be obtained with similar pore sizes [33]. Given their atomic thickness and proper pore sizes, the He purification of this group of 2D MOF is highly expected.

In this work, using combined first-principles calculations and MD simulations, we theoretically demonstrated that the 2D Fe-PTC MOF and its analogues Ni-PTC MOF can efficiently separate He from natural gas and inert gases. The He permeance of Fe/Ni-PTC MOF reached $\sim 6 \times 10^{-4} \mathrm{~mol} \mathrm{~s}^{-1} \mathrm{~m}^{-2} \mathrm{~Pa}^{-1}$. It is worth mentioning that this permeability is five orders of magnitude higher than the industrially acceptable value $\left(6.9 \times 10^{-9} \mathrm{~mol} \mathrm{~s}^{-1} \mathrm{~m}^{-2} \mathrm{~Pa}^{-1}\right)$, indicating its potential in industrial application. Moreover, the $\mathrm{He} / \mathrm{N}_{2}$ selectivity is estimated to be $10^{15} \sim 10^{17}$, higher than most of the previously proposed 2D porous membranes. Hence, our results provide a new type of competitive He separation membranes with promising industrial applications.

\section{Computational Methods}

The Vienna ab initio simulation program (VASP) in the framework of density functional theory (DFT) is used to perform all first-principles calculations [34,35]. The projectedaugmented wave (PAW) potential [36] was employed to describe the electron-ion interaction. The Perdew-Burke-Ernzerhof (PBE) functional under the generalized gradient approximation (GGA) was used to describe the electron-electron interaction [37]. The weak van der Waals interaction between the gas molecules and the Fe/Ni-PTC membrane was corrected by the Grimme method (DFT-D2) [38]. The energy cutoff was set to be $500 \mathrm{eV}$ and iterative convergences of energy and force were $10^{-5} \mathrm{eV}$ and $10^{-2} \mathrm{eV} / \AA$. In 
order to prevent the interaction between adjacent images, a $20 \AA$ vacuum zone was applied in the $z$ direction. A k-point mesh of $5 \times 5 \times 1$ was chosen for sampling the Brillouin zone for the unit cell [39]. The convergence of the system energy with respect to energy cutoff and the k-point mesh has been tested and shown in Table S1. For the pristine membrane, fully structural optimization was performed. For the adsorption interaction between gases and membranes, the cell vectors were fixed as negligible influence (membrane areas or adsorption energies) was observed upon gas adsorption (Table S2). Meanwhile, the $\mathrm{z}$-coordinates of the membranes were frozen to maintain a planar surface, while the $\mathrm{x}$ and $y$-coordinates of the membrane and the coordinates of the gas molecules were fully relaxed. The cohesive energies of these two MOF membranes and the adsorption energies of gas molecules adsorbed on a membrane are all obtained from single point energy calculation. The climbing image nudged elastic band (cNEB) method was adopted for searching the minimum energy pathway of the gas molecule passing through the 2D MOF membrane [40]. In the transition state calculation, we used convergence criteria of energy and force of $10^{-5} \mathrm{eV}$ and $0.02 \mathrm{eV} / \AA$. Moreover, 5 images were used along the minimum energy pathway, and the z-coordinates of the membrane were kept frozen to maintain a planar surface.

The molecular dynamics (MD) simulations were performed within the GROMACS package using the universal force field (UFF) [41,42]. The three partial charge models for $\mathrm{CO}_{2}$ and $\mathrm{N}_{2}$ molecules were used to account for the quadrupole distinction of the $\mathrm{CO}_{2}$ and $\mathrm{N}_{2}$ molecules (Table S3) [43,44]. The atomic charges of $\mathrm{CH}_{4}$ and $\mathrm{CO}$ were adopted from previous work [17], and are shown in Table S4. The atomic charges of Fe/Ni-PTC membranes were obtained from the ESP fitting based on Merz-Kollman scheme by Gaussian 09 at the B3LYP/6-31g(d) level [45]. The detailed charge information for the Fe/Ni-PTC is shown in Figure S1 in the ESI. In the molecular dynamics simulation system, seven prototype gas molecules, including $\mathrm{He}, \mathrm{Ne}, \mathrm{CO}_{2}, \mathrm{~N}_{2}, \mathrm{Ar}, \mathrm{CO}$, and $\mathrm{CH}_{4}$ (50 for each molecule), were randomly placed into a simulation box sandwiched by a graphene sheet and a Fe/Ni-PTC membrane. The graphene sheet acts as a piston in the system, which was applied with a constant force of $115.1 \mathrm{~kJ} \mathrm{~mol}^{-1} \mathrm{~nm}^{-1}$ (equivalent to a constant pressure of $100 \mathrm{Bar}$ ), while the coordinates of the Fe/Ni-PTC membrane were kept frozen. The volume of the simulation box is $4.068 \mathrm{~nm} \times 4.698 \mathrm{~nm} \times 90 \mathrm{~nm}$, and 3D periodic boundary conditions were applied.

The potential of mean force (PMF) [46] for $\mathrm{He}$ and $\mathrm{N}_{2}$ gases are calculated by means of the umbrella sampling method. Sixteen sampling windows with $0.1 \mathrm{~nm}$ intervals were taken on one side of the MOF membrane, and the total sampling length was $1.5 \mathrm{~nm}$. For each sampling point, the position of the selected gas molecule was restrained using a harmonic potential along the reaction coordinate ( $\mathrm{z}$ direction). The system was firstly equilibrated for $1 \mathrm{~ns}$, and then the PMF was generated from $20 \mathrm{~ns}$ simulated force data in the canonical ensemble using the weighted histogram analysis method [47].

\section{Results and Discussion}

\subsection{The Structural Stability of Fe/Ni-PTC}

The metal-PTC 2D MOF has several members depending on the specific types of transition metal in the nodes. In this study, we took Fe-PTC and Ni-PTC as representative models to study their filtration performance for He separation. The optimized structures at DFT level are shown in Figure 1, where the lattice constants for Fe-PTC and Ni-PTC are determined to be $a=b=1.356 \mathrm{~nm}$ with the angle between them $\alpha=120^{\circ}$, in good agreement with previous studies [33]. The diameters of the pore are $5.65 \AA$ and $5.67 \AA$ for Fe-PTC and Ni-PTC, respectively. For the Fe-PTC, the lengths of C-C bond, C-S bond, and Fe-S bond are $1.450 \AA, 1.729 \AA$, and $2.094 \AA$, while for the Ni-PTC, that of the C-C, C-S, and Ni-S bonds are $1.449 \AA, 1.710 \AA$, and $2.128 \AA$, which are all consistent with previously reported values $[32,33]$. The cohesive energy is used to examine the structural stability of 
the Fe/Ni-PTC monolayer, which represents the energy required to break the monolayer down into individual atoms, as defined by [48]:

$$
E_{c o h}=\left(n_{1} E_{c}+n_{2} E_{s}+n_{3} E_{F e / N i}-E_{m e m}\right) /\left(n_{1}+n_{2}+n_{3}\right)
$$

where $E_{c}, E_{S}, E_{\mathrm{Fe} / \mathrm{Ni}}$, and $E_{m e m}$ denote the energies of a single $\mathrm{C}$ atom, a single $\mathrm{S}$ atom, a single $\mathrm{Fe} / \mathrm{Ni}$ atom, and the total energy of the Fe/Ni-PTC monolayer, respectively; $n_{1}, n_{2}$, and $n_{3}$ denote the total numbers of the $\mathrm{C}$ atoms, the $\mathrm{S}$ atoms, and the $\mathrm{Fe} / \mathrm{Ni}$ atoms in the unit cell. The cohesive energy of the monolayer Fe-PTC was computed to be $7.10 \mathrm{eV} /$ atom while that of Ni-PTC was $7.21 \mathrm{eV} /$ atom, slightly higher than that of Fe-PTC, indicating its high energetic stability and the possibility of experimental synthesis. Moreover, a previous study has shown that both Fe-PTC and Ni-PTC are all thermally stable [33], which is crucial for gas separation.

(a)
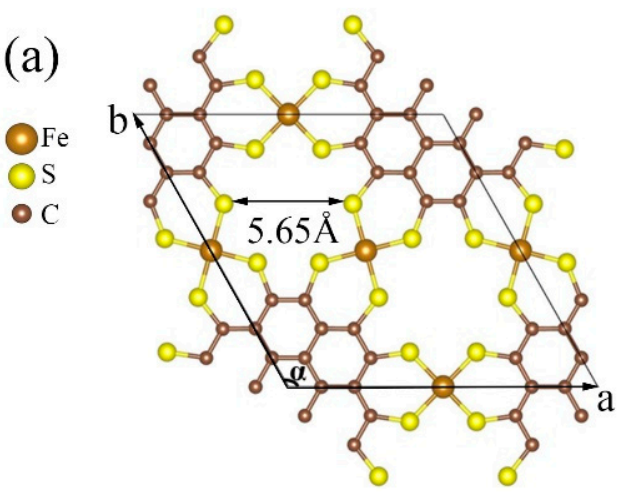

(c)

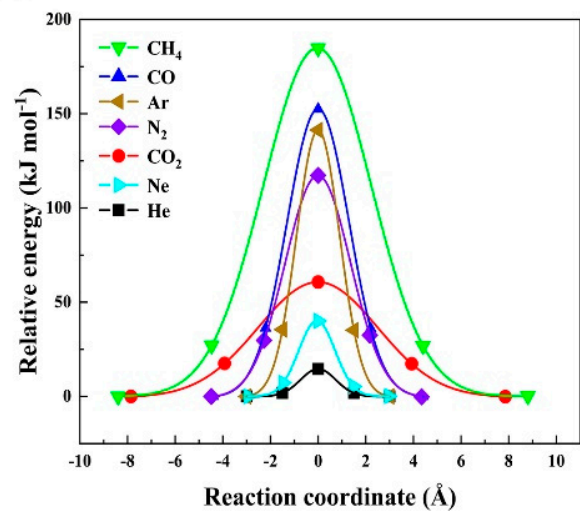

(b)

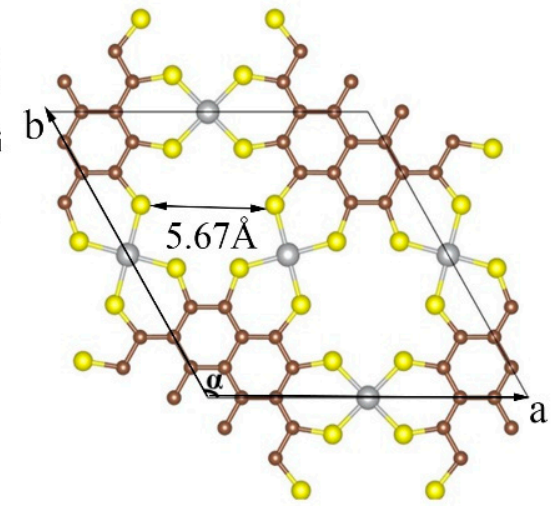

(d)

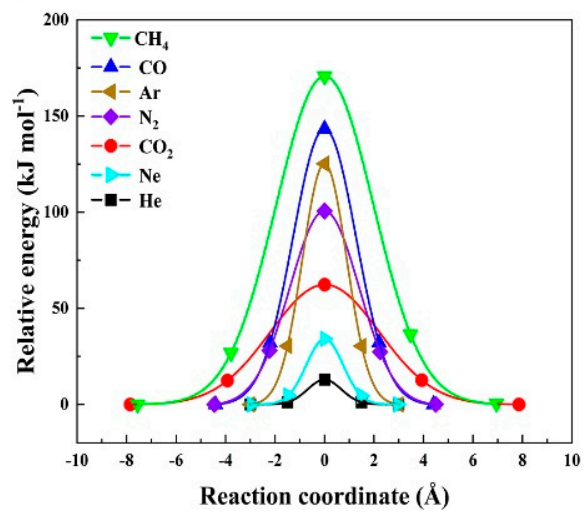

Figure 1. The top views of the optimized unit cell of the (a) Fe-PTC and (b) Ni-PTC monolayer, where $\vec{a}$ and $\vec{b}$ represent the cell vectors and $\alpha$ represents the angle between them. The energy profiles for seven prototype gas molecules translocating the (c) Fe-PTC and (d) Ni-PTC membranes.

\subsection{DFT Energy Barriers}

In this study, several prototype gas molecules $\left(\mathrm{He}, \mathrm{Ne}, \mathrm{CO}_{2}, \mathrm{CO}, \mathrm{N}_{2}, \mathrm{Ar}\right.$, and $\left.\mathrm{CH}_{4}\right)$ from the by-product during natural gas exploitation [49] were selected to assess the $\mathrm{He}$ filtration performance of Fe-PTC and Ni-PTC membranes. Prior to exploring the energy barrier of an individual gas molecule penetrating the Fe/Ni-PTC membrane, the adsorption ability of Fe/Ni-PTC monolayers to each gas molecule has been investigated. The adsorption energy between the Fe/Ni-PTC membrane and a gas molecule can be expressed by the following formula:

$$
E_{a d}=E_{g a s+m e m}-E_{g a s}-E_{m e m}
$$


where $E_{g a s}$ represents the energy of an individual gas molecule, $E_{m e m}$ represents the energy of a pristine membrane, both of which were obtained from the single point energy calculations computed from the geometry-optimized structures of the isolated components, and $E_{\text {gas }+ \text { mem }}$ represents the total energies of a gas molecule adsorbed on the membrane at the most stable adsorption state. The adsorption energy and adsorption height of the most stable state for each molecule on the Fe-PTC and Ni-PTC membranes are summarized in Tables 1 and 2. It can be seen that the adsorption energy ranges from -2 to $-17 \mathrm{~kJ} \mathrm{~mol}^{-1}$ and the adsorption height is in the range from 2.8 to $3.0 \AA$, indicating that the gas molecules are physically adsorbed on the Fe/Ni-PTC membrane. Among these molecules, the $\mathrm{He}$ molecule has the weakest interaction with the Fe/Ni-PTC $\left(-2.60 /-2.31 \mathrm{~kJ} \mathrm{~mol}^{-1}\right)$, which may facilitate the diffusion of He through the Fe/Ni-PTC membrane. The illustration of the adsorption state of each gas molecule on the Fe/Ni-PTC membrane can be found in Figure S2, where guest molecules uniformly prefer to adsorb on the pore area. Thus, the transition metal cations ( $\mathrm{Fe}$ or $\mathrm{Ni}$ ) do not play an important role on stabilization of the guest molecules, because no direct interactions between them were formed.

Table 1. The adsorption height $\left(\mathrm{H}_{0}\right)$, the corresponding adsorption energy $\left(\mathrm{E}_{a d}\right)$ between the gas molecule and the Fe-PTC monolayer, and the energy barriers $\left(\mathrm{E}_{b}\right)$ of the seven gas molecules translocating the Fe-PTC monolayer.

\begin{tabular}{cccc}
\hline Gas Molecule & $\mathbf{H}_{\mathbf{0}}(\mathbf{A})$ & $\left.\mathbf{E}_{\boldsymbol{a d}} \mathbf{( \mathbf { k J ~ m o l }} \mathbf{~ m o l}^{-\mathbf{1}}\right)$ & $\left.\mathbf{E}_{\boldsymbol{b}} \mathbf{( \mathbf { k J ~ m o l }} \mathbf{~ m o l}^{-\mathbf{1}}\right)$ \\
\hline $\mathrm{He}$ & 3.000 & -2.60 & 14.64 \\
$\mathrm{Ne}$ & 2.901 & -4.43 & 40.26 \\
$\mathrm{CO}_{2}$ & 3.337 & -9.25 & 60.87 \\
$\mathrm{~N}_{2}$ & 2.836 & -13.20 & 117.61 \\
$\mathrm{Ar}$ & 2.987 & -10.98 & 141.78 \\
$\mathrm{CO}$ & 3.000 & -13.97 & 152.96 \\
$\mathrm{CH}_{4}$ & 2.950 & -14.74 & 185.42 \\
\hline
\end{tabular}

Table 2. The adsorption height $\left(\mathrm{H}_{0}\right)$, the corresponding adsorption energy $\left(\mathrm{E}_{a d}\right)$ between the gas molecule and the Ni-PTC monolayer, and the energy barriers $\left(\mathrm{E}_{b}\right)$ of the seven gas molecules translocating the Ni-PTC monolayer.

\begin{tabular}{|c|c|c|c|}
\hline Gas Molecule & $\mathrm{H}_{0}(\AA)$ & $\mathrm{E}_{a d}\left(\mathrm{~kJ} \mathrm{~mol}^{-1}\right)$ & $\mathrm{E}_{b}\left(\mathrm{~kJ} \mathrm{~mol}^{-1}\right)$ \\
\hline $\mathrm{He}$ & 2.997 & -2.31 & 13.00 \\
\hline $\mathrm{Ne}$ & 3.000 & -4.43 & 34.19 \\
\hline $\mathrm{CO}_{2}$ & 2.929 & -6.84 & 62.51 \\
\hline $\mathrm{N}_{2}$ & 2.918 & -13.00 & 100.95 \\
\hline $\mathrm{Ar}$ & 3.000 & -10.79 & 125.61 \\
\hline $\mathrm{CO}$ & 2.999 & -13.87 & 143.91 \\
\hline $\mathrm{CH}_{4}$ & 2.683 & -16.28 & 171.36 \\
\hline
\end{tabular}

With the most stable adsorption state, the translocating pathway of an individual gas molecule through the Fe/Ni-PTC membrane was searched by the cNEB approach [40]. The energy barrier $\left(E_{b}\right)$ of a gas molecule passing through the membrane can be defined as [50]:

$$
E_{b}=E_{T S}-E_{S S}
$$

where $E_{T S}$ denotes the energy of a gas molecule and the Fe/Ni-PTC membrane at the transition state (namely, the energy saddle point) and $E_{S S}$ represents that at the most stable adsorption state. The energy profiles of all seven gas molecules passing through the Fe/Ni-PTC membrane are plotted in Figure 1c,d respectively, and the energy barriers are summarized in Tables 1 and 2. It is obvious that the energy barriers for seven gases are increased following the order of $\mathrm{He}<\mathrm{Ne}<\mathrm{CO}_{2}<\mathrm{N}_{2}<\mathrm{Ar}<\mathrm{CO}<\mathrm{CH}_{4}$, where $\mathrm{He}$ has the lowest energy barriers to pass through the Fe-PTC $\left(14.64 \mathrm{~kJ} \mathrm{~mol}^{-1}\right)$ and Ni-PTC $\left(13.00 \mathrm{~kJ} \mathrm{~mol}^{-1}\right)$ membranes, respectively. The electron density difference maps for the 
transition state for both gas-Fe-PTC and gas-Ni-PTC systems in Figure S3 also show that the coupling between $\mathrm{He}$ and the membranes are the weakest, while that between $\mathrm{CH}_{4}$ and the membranes are the strongest, because the most significant electron transfer happened between $\mathrm{CH}_{4}$ and the membranes. Moreover, for electron density difference maps at the states near the transition states in Figure S4, dipole-shaped interactions can be clearly observed for $\mathrm{CO}_{2}$ and $\mathrm{N}_{2}$, which are induced by the inherent electric field of the membranes. These results reveal that $\mathrm{He}$ is more inclined to be separated from other gas molecules by the Fe/Ni-PTC membrane.

\subsection{Electron Density Isosurfaces}

To better understand the different barriers of Fe/Ni-PTC to seven gas molecules, we then calculated the electron density of gas molecules interacting with the Fe-PTC monolayer, because electron density overlap between them results in repulsive interaction between the gas molecules and the membrane [13]. As shown in Figure 2, with isovalue of $0.01 \mathrm{e} \AA^{-3}$, there is no obvious electron density overlap between the He molecule and the Fe-PTC membrane, which is well consistent with the lowest energy barrier for He diffusing through the Fe-PTC membrane. For other molecules, clear electron density overlap is observed, resulting in higher energy barriers. The electron overlap between $\mathrm{CH}_{4}$ and Fe-PTC membrane is the most significant, thus the highest energy barrier was obtained for $\mathrm{CH}_{4}$ translocating the Fe-PTC membrane. The electron density isosurfaces of the gas molecule interacting with the Ni-PTC monolayer are depicted in Figure S5, where a similar trend has been observed.

(a) $\mathrm{He}$

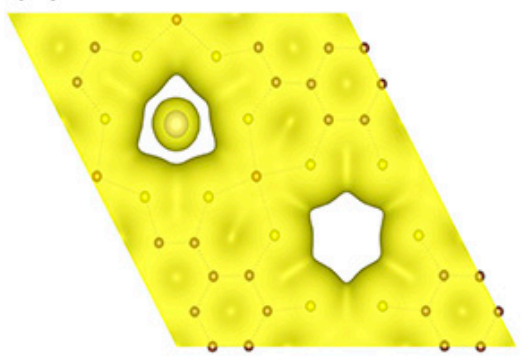

(d) $\mathrm{N}_{2}$

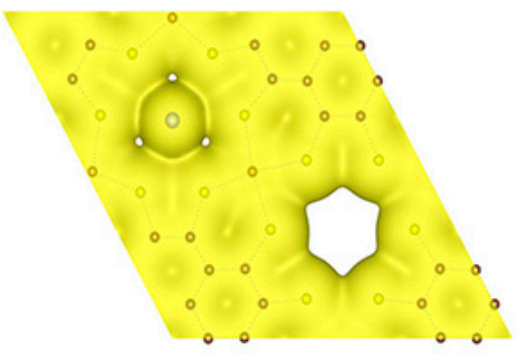

(b) $\mathrm{Ne}$

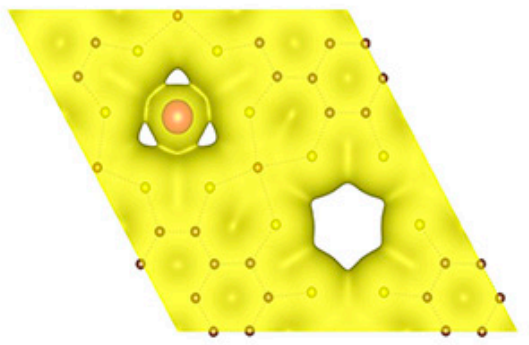

(e) $\mathrm{Ar}$

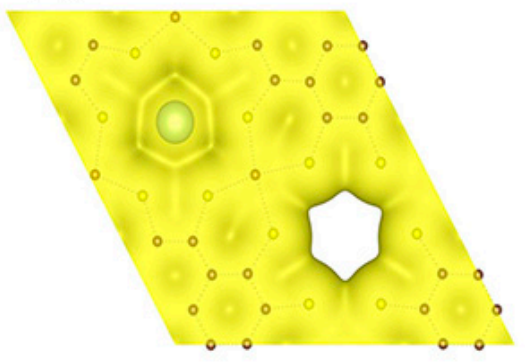

(c) $\mathrm{CO}_{2}$

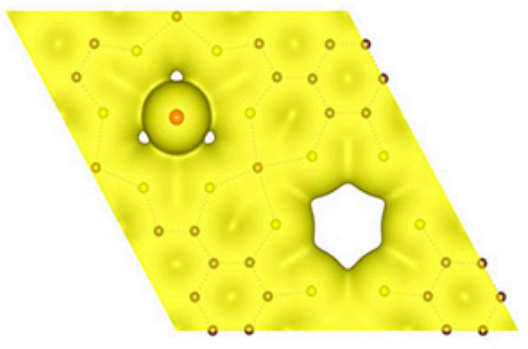

(f) $\mathrm{CH}_{4}$

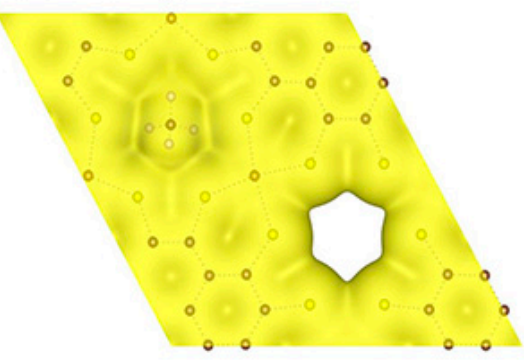

Figure 2. Electron density isosurfaces for the gas molecules: (a) $\mathrm{He},(\mathbf{b}) \mathrm{Ne},(\mathbf{c}) \mathrm{CO}_{2},(\mathbf{d}) \mathrm{N}_{2},(\mathbf{e}) \mathrm{Ar}$ and (f) $\mathrm{CH}_{4}$ translocating the Fe-PTC membrane (isovalue of $0.01 \AA^{-3}$ ).

\subsection{DFT Selectivity of He}

Based on the energy barriers of gas molecule translocating the Fe/Ni-PTC membrane, the selectivity of the He molecule to other gases can be evaluated via the Arrhenius equation [51]:

$$
S_{H e / g a s}=\frac{r_{H e}}{r_{g a s}}=\frac{A_{H e} e^{-E_{H e} / R T}}{A_{g a s} e^{-E_{g a s} / R T}}
$$


where $r, A$, and $E$ represent the diffusion rate, the diffusion prefactor, and the diffusion energy barrier summarized in Table 1 . The diffusion prefactor of all gases in this work was assumed to be $10^{11} \mathrm{~s}^{-1}$, following previous studies [52,53]. The diffusion rates of all the gas molecules and the selectivity of He over other gas molecules as a function of temperature are shown in Figure 3. With the increase of temperature, the diffusion rate of gas molecules uniformly rises, which can be attributed to the increased kinetic energy of gas molecules in the high-temperature region. In addition, the selectivity of He over other molecules of the $\mathrm{Fe} / \mathrm{Ni}$-PTC membrane decreases with the increase of temperature.

(a)

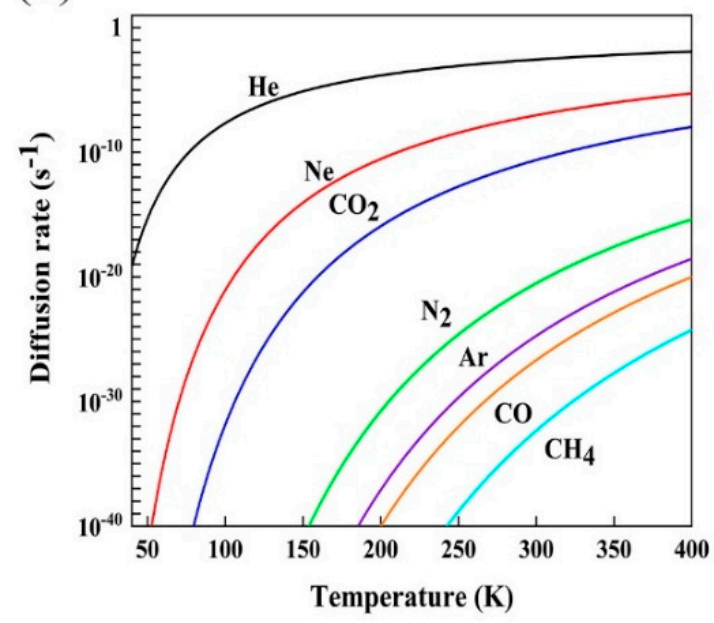

(c)

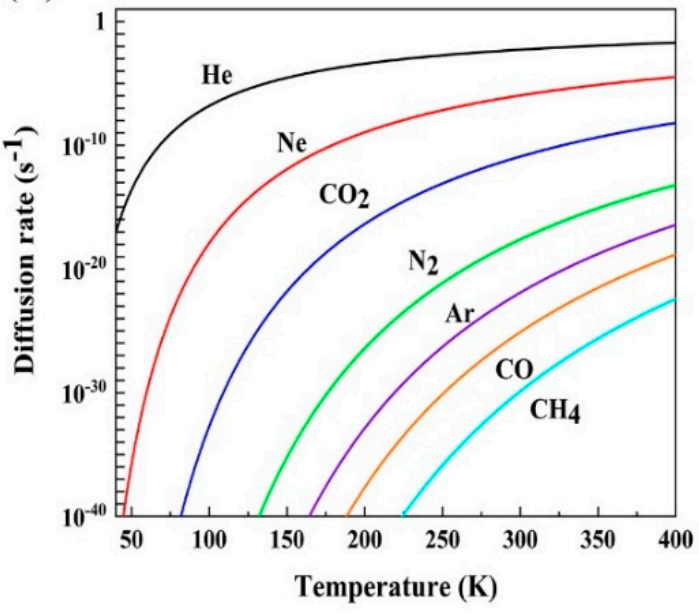

(b)

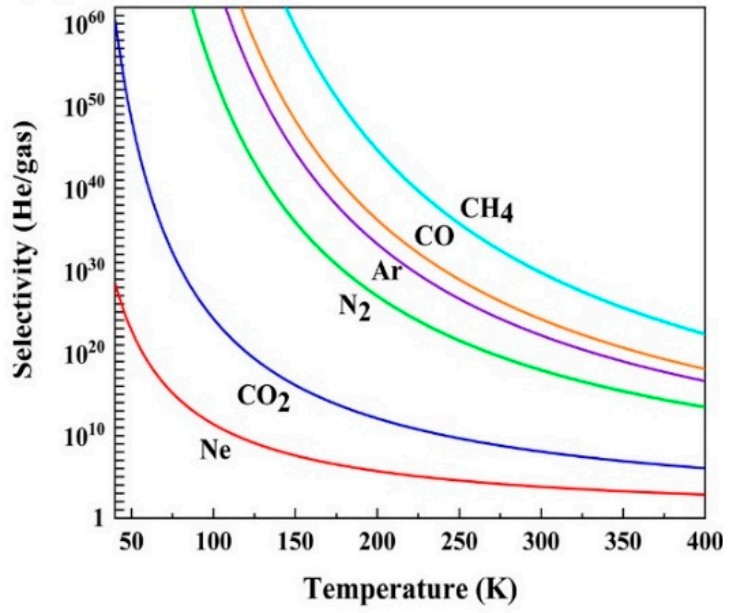

(d)

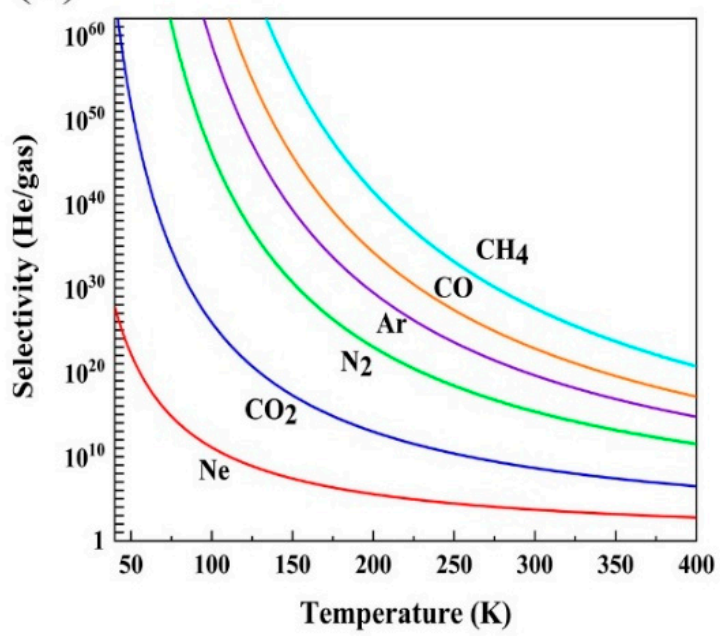

Figure 3. (a) The diffusion rates and (b) the selectivity for gases to pass through the Fe-PTC membrane as a function of temperature; (c) The diffusion rates and (d) the selectivity for gases to pass through the Ni-PTC membrane as a function of temperature. Different colors denote different gas molecules.

\subsection{Simulations on He Filtration}

For industrial He separation, the operation is normally carried out at room temperature [54]. Therefore, MD simulations were conducted to verify the separation performance of Fe/Ni-PTC membranes at $300 \mathrm{~K}$. In the simulation model shown in Figure $4 \mathrm{a}, 50 \mathrm{He}$, $50 \mathrm{Ne}, 50 \mathrm{Ar}, 50 \mathrm{CO}, 50 \mathrm{CO}_{2}, 50 \mathrm{~N}_{2}$, and $50 \mathrm{CH}_{4}$ were mixed and randomly distributed between a graphene piston and a Fe/Ni-PTC membrane. Three parallel trajectories of 90 ns have been generated and the results are plotted in Figure $4 b, c$. It can be seen that during the 90 ns simulation, consecutive events of He passing through the Fe/Ni-PTC membrane were monitored and after 90 ns, nearly all of the He molecules had penetrated through the 
$\mathrm{Fe} / \mathrm{Ni}$-PTC membrane. In contrast, other molecules remained between the two membranes as indicated by the green lines. The insets show the He flow rates perpendicular to the membranes, which decrease with time as increasingly more He molecules have escaped away. Therefore, the results from the MD simulation demonstrated that Fe/Ni-PTC is highly selective to He over other gas molecules. The representative trajectory snapshots are shown in Figures S6 and S7 in the ESI.

(a)

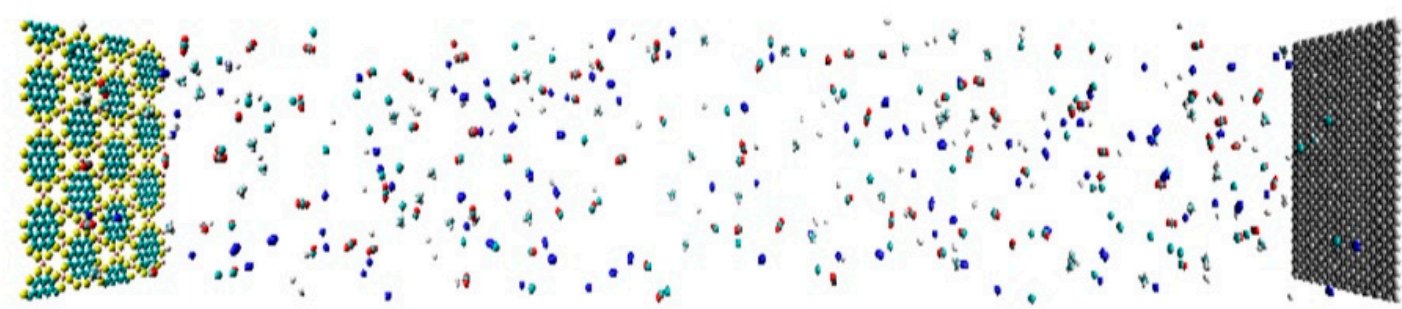

$\mathrm{Fe} / \mathrm{Ni}-\mathrm{PTC}$

graphene piston

(b)

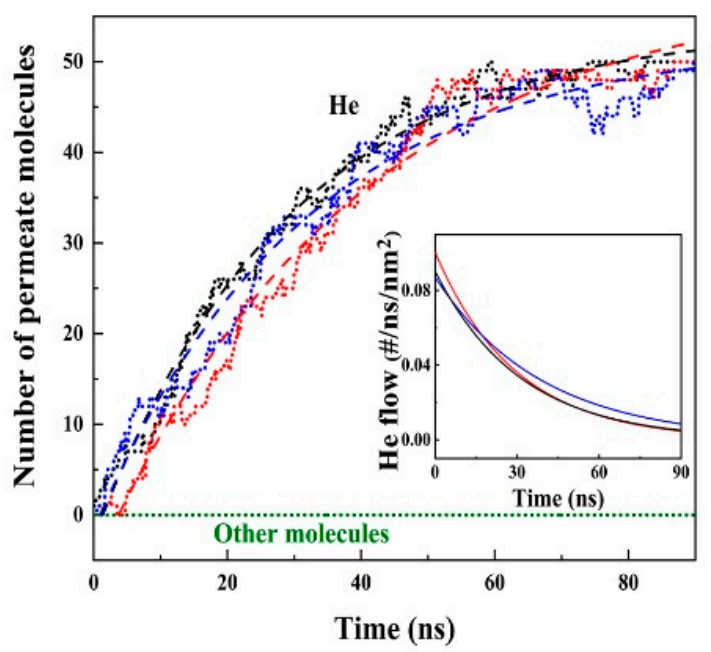

(c)

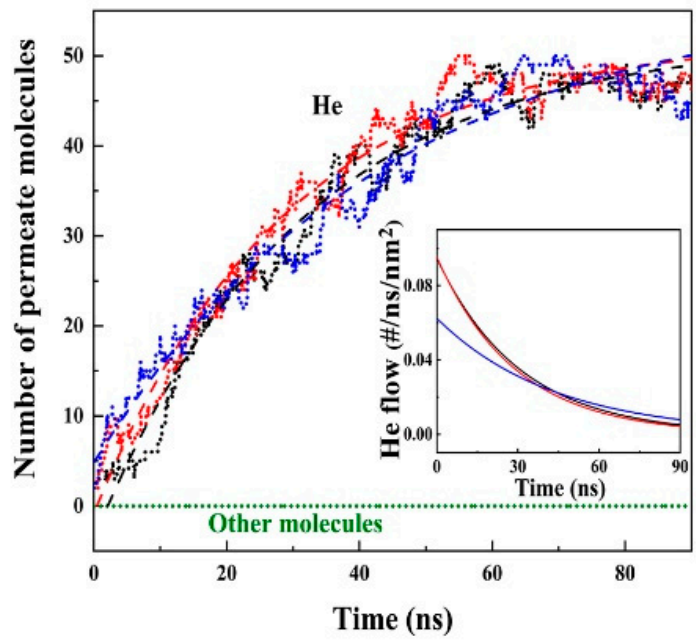

Figure 4. (a) The snapshot of the simulation model; pure He permeation by (b) Fe-PTC and (c) Ni-PTC membranes at $300 \mathrm{~K}$, where individual results obtained from three independent trajectories are represented by red, blue, and black dots. The dashed lines are the numerical fitted results. The insets show the gas flow rates calculated from the numerical fitted results.

In addition to selectivity, He permeance is another indicative factor to judge the separation efficiency of a membrane. Thus, we further calculated the He permeance of $\mathrm{Fe} / \mathrm{Ni}$-PTC membrane at temperatures ranging from $200-500 \mathrm{~K}$, following the method reported in a previous work [55] which can be found in the ESI. The results of He permeance are listed in Table 3. It can be seen that as the temperature increases, the permeance gradually increased from $10^{-4}$ to $10^{-3} \mathrm{~mol} \mathrm{~s}^{-1} \mathrm{~m}^{-2} \mathrm{~Pa}^{-1}$, which is attributed to the increased kinetic energy of He particles at high temperatures. At room temperature of $300 \mathrm{~K}$, the permeance of He reached $\sim 6 \times 10^{-4} \mathrm{~mol} \mathrm{~s}^{-1} \mathrm{~m}^{-2} \mathrm{~Pa}^{-1}$ for both Fe-PTC and NiPTC membrane, which is five orders of magnitude higher than the industrially acceptable value $\left(6.79 \times 10^{-9} \mathrm{~mol} \mathrm{~s}^{-1} \mathrm{~m}^{-2} \mathrm{~Pa}^{-1}\right)$ [56], implying the plausibility of the $\mathrm{Fe} / \mathrm{Ni}$-PTC membrane for the industrial applications. 
Table 3. He permeance $\left(\mathrm{mol} \mathrm{s}^{-1} \mathrm{~m}^{-2} \mathrm{~Pa}^{-1}\right)$ at the temperature range of 200-500 K.

\begin{tabular}{ccc}
\hline Membrane & Temperature (K) & Permeance \\
\hline \multirow{3}{*}{ Fe-PTC } & 200 & $2.9 \times 10^{-4}$ \\
& 300 & $6.3 \times 10^{-4}$ \\
& 400 & $8.9 \times 10^{-4}$ \\
& 500 & $1.3 \times 10^{-3}$ \\
\hline \multirow{2}{*}{ Ni-PTC } & 200 & $3.6 \times 10^{-4}$ \\
& 300 & $6.6 \times 10^{-4}$ \\
& 400 & $9.2 \times 10^{-4}$ \\
& 500 & $1.5 \times 10^{-3}$ \\
\hline
\end{tabular}

\subsection{Comparison between Membranes}

After the pre-treatment of natural gas, the major component in the remaining gas stream is $\mathrm{N}_{2}$. Thus, the selectivity of the Fe/Ni-PTC for He over $\mathrm{N}_{2}$ is of great significance in practical applications. We compared the He permeance and the $\mathrm{He} / \mathrm{N}_{2}$ selectivity of both Fe-PTC and Ni-PTC membrane with previously proposed nanoporous membranes to evaluate the He separation efficiency of the two MOFs. As shown in Table 4, it is obvious that although the Fe/Ni-PTC has relatively lower He permeance, the $\mathrm{He} / \mathrm{N}_{2}$ selectivity of $\mathrm{Fe} / \mathrm{Ni}-\mathrm{PTC} \mathrm{MOF}$ is significantly higher than those of $\mathrm{g}-\mathrm{C}_{2} \mathrm{O}, \mathrm{C}_{2} \mathrm{~N}$ and $6 \mathrm{~N}-\mathrm{PG}$ membranes. While compared to the CTF-0 membrane, the selectivity of Fe/Ni-PTC MOF is lower, but the permeance is three orders of magnitude higher. It should be noted that compared to the IGP membrane, with almost the same permeance, the He selectivity of Fe/Ni-PTC is higher by five orders of magnitude, indicating its superior performance for He harvest.

Table 4. Comparison results of He permeance (GPU) and the $\mathrm{He} / \mathrm{N}_{2}$ selectivity between Fe/Ni-PTC MOF and previously proposed porous membranes at $300 \mathrm{~K} .\left(1 \mathrm{GPU}=3.3 \times 10^{-10} \mathrm{~mol} \mathrm{~s}^{-1} \mathrm{~m}^{-2} \mathrm{~Pa}^{-1}\right)$.

\begin{tabular}{ccc}
\hline Membrane & Permeance & Selectivity \\
\hline $\mathrm{Fe} \mathrm{PTC}^{1}$ & $1.9 \times 10^{6}$ & $9.1 \times 10^{17}$ \\
$\mathrm{Ni}-\mathrm{PTC}^{1}$ & $2.1 \times 10^{6}$ & $2.2 \times 10^{15}$ \\
${\mathrm{~g}-\mathrm{C}_{2} \mathrm{O}^{2}}^{2}$ & $1.0 \times 10^{7}$ & $1.5 \times 10^{6}$ \\
$\mathrm{IGP}^{3}$ & $2.0 \times 10^{6}$ & $1.0 \times 10^{12}$ \\
$\mathrm{CTF}^{4}$ & $1.0 \times 10^{3}$ & $2.0 \times 10^{27}$ \\
$\mathrm{C}_{2} \mathrm{~N}^{5}$ & $1.0 \times 10^{7}$ & $3.0 \times 10^{12}$ \\
$6 \mathrm{~N}-\mathrm{PG}^{6}$ & $6.9 \times 10^{7}$ & $6.0 \times 10^{8}$
\end{tabular}

${ }^{1}$ This study. ${ }^{2}$ Ref. [15]. ${ }^{3}$ Ref. [17]. ${ }^{4}$ Ref. [14]. ${ }^{5}$ Ref. [16]. ${ }^{6}$ Ref. [57].

\subsection{Free Energy Barrier Analysis}

The above results have demonstrated that the Fe/Ni-PTC membrane have excellent selectivity and permeance for He separation, both in the high selectivity and permeance. To get a deeper insight into the improved $\mathrm{He} / \mathrm{N}_{2}$ selectivity and He permeance at room temperature, we have estimated the free energy barriers by calculating the PMF of $\mathrm{He}$ and $\mathrm{N}_{2}$ passing through the $\mathrm{Fe} / \mathrm{Ni}-\mathrm{PTC}$ membrane and the results are summarized in Figure 5. As can be seen, the free energy barrier values for He penetrating Fe/Ni-PTC membrane are 5.62 and $5.18 \mathrm{k}_{\mathrm{B}} \mathrm{T}$, respectively, which are much lower than those of $\mathrm{N}_{2}$ (73.8 and $66.2 \mathrm{k}_{\mathrm{B}} \mathrm{T}$ ), resulting in both the high $\mathrm{He} / \mathrm{N}_{2}$ selectivity and high He permeance. It is worth noting that compared with the energy barriers based on DFT calculation for $\mathrm{N}_{2}$ (117.61/100.95 $\mathrm{kJ} \mathrm{mol}^{-1}$, equivalent to $47.2 / 40.5 \mathrm{k}_{\mathrm{B}} \mathrm{T}$ for Fe-PTC and Ni-PTC respectively), the free energy barriers obtained from PMF analysis are increased. This is because the temperature-related conformational entropy for rod-like molecules such as $\mathrm{N}_{2}$ is explicitly considered. 
(a)

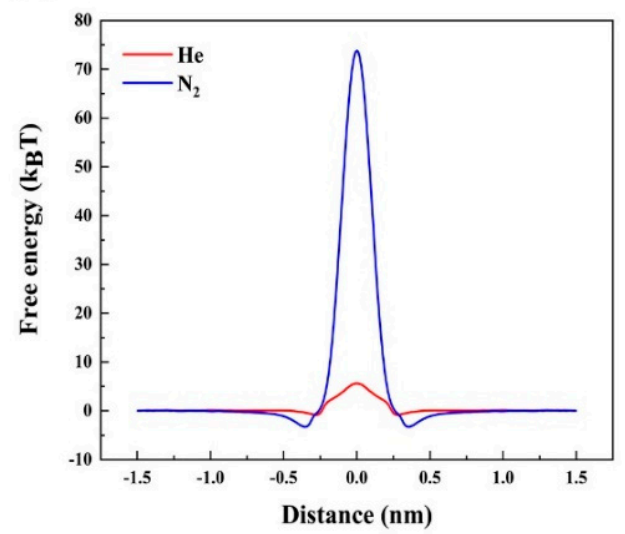

(b)

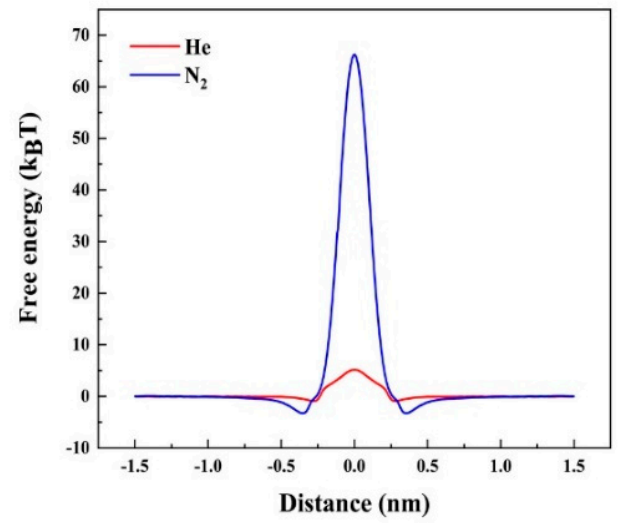

Figure 5. The PMF of He and $\mathrm{N}_{2}$ passes through the (a) Fe-PTC and (b) Ni-PTC membranes by umbrella sampling.

\section{Conclusions}

To conclude, we performed combined first-principles calculations and MD simulations to theoretically investigate the feasibility of the 2D Fe/Ni-PTC MOF materials for He separation from natural gas and other noble gases. High permeance $\left(\sim 6 \times 10^{-4} \mathrm{~mol} \mathrm{~s}^{-1} \mathrm{~m}^{-2} \mathrm{~Pa}^{-1}\right)$ and $\mathrm{He} / \mathrm{N}_{2}$ selectivity $\left(10^{15} \sim 10^{17}\right)$ of $\mathrm{Fe} / \mathrm{Ni}-\mathrm{PTC}$ MOF are predicted, superior to most of the previously proposed 2D porous membranes. Moreover, quantitative free energy analysis indicates that the free energy barriers for He passing through the Fe/Ni-PTC MOF are only $\sim 5 \mathrm{k}_{\mathrm{B}} \mathrm{T}$, which is significantly lower than that of $\mathrm{N}_{2}\left(\sim 70 \mathrm{k}_{\mathrm{B}} \mathrm{T}\right)$, resulting in the high selectivity for He separation at room temperature. Overall, our results have demonstrated that the newly synthesized 2D Fe-PTC and its analogue Ni-PTC are promising membranes for He separation, which might have great prospects in industrial production.

Supplementary Materials: The following are available online at https:/ / www.mdpi.com/article/10.339 0/membranes11120927/s1, Figure S1: Atomic charges, Figure S2: The schematic diagram of the adsorption states, Figures S3 and S4: The electron density difference maps, Figure S5: Electron-density isosurfaces, Figures S6 and S7: Snapshots, Figure S8: Model for calculating permeance, Figure S9: Number of permeated He molecules versus simulation time. Table S1: The convergence of the energy, Table S2: The vector changes and the energy differences, Table S3: Force field parameters, Table S4: Atomic charges. Supplementary Method: Method for calculating permeance.

Author Contributions: Conceptualization, Y.Q.; methodology, J.W.; software, Y.L. (Yixiang Li); validation, Y.L. (Yixiang Li) and J.W.; formal analysis, J.W.; investigation, J.W.; data curation, J.W.; writing—original draft preparation, J.W., Y.Q. and W.L.; writing—review \& editing, Y.Q. and J.G.; supervision, Y.Q., J.G. and W.L.; project administration, Y.Y., Y.L. (Yongqiang Li) and J.G.; funding acquisition, Y.Q., W.L. and M.Z. All authors have read and agreed to the published version of the manuscript.

Funding: This research was funded by the National Natural Science Foundation of China, grant number Nos.12074215, 11874238, the Natural Science Foundation of Shandong Province of China (No. ZR2020JQ04) and the Taishan Scholar Project of Shandong Province.

Institutional Review Board Statement: Not applicable.

Data Availability Statement: The data that support the findings of this study are available from the corresponding author upon reasonable request.

Acknowledgments: We would like to acknowledge all support for this work by the Shandong University, the National Natural Science Foundation of China and the Taishan Scholar Project of Shandong Province.

Conflicts of Interest: The authors declare no conflict of interest. 


\section{References}

1. Kaplan, K.H. Helium shortage hampers research and industry. Phys. Today 2007, 60, 31. [CrossRef]

2. Cho, A. Helium-3 shortage could put freeze on low-temperature research. Science 2009, 326, 778-779. [CrossRef]

3. Nuttall, W.J.; Clarke, R.H.; Glowacki, B.A. Resources: Stop squandering helium. Nature 2012, 485, 573-575. [CrossRef] [PubMed]

4. Smith, Z.P.; Tiwari, R.R.; Dose, M.E.; Gleason, K.L.; Murphy, T.M.; Sanders, D.F.; Gunawan, G.; Robeson, L.M.; Paul, D.R.; Freeman, B.D. Influence of Diffusivity and Sorption on Helium and Hydrogen Separations in Hydrocarbon, Silicon, and Fluorocarbon-Based Polymers. Macromolecules 2014, 47, 3170-3184. [CrossRef]

5. Yuan, W.; Chen, J.; Shi, G. Nanoporous graphene materials. Mater. Today 2014, 17, 77-85. [CrossRef]

6. Hosseini, S.S.; Teoh, M.M.; Chung, T.S. Hydrogen separation and purification in membranes of miscible polymer blends with interpenetration networks. Polymer 2008, 49, 1594-1603. [CrossRef]

7. Hu, W.; Wu, X.; Li, Z.; Yang, J. Porous silicene as a hydrogen purification membrane. Phys. Chem. Chem. Phys 2013, 15, 5753-5757. [CrossRef]

8. Koenig, S.P.; Wang, L.; Pellegrino, J.; Bunch, J.S. Selective molecular sieving through porous graphene. Nat. Nanotechnol. 2012, 7, 728-732. [CrossRef] [PubMed]

9. Bunch, J.S.; Verbridge, S.S.; Alden, J.S.; van der Zande, A.M.; Parpia, J.M.; Craighead, H.G.; McEuen, P.L. Impermeable atomic membranes from graphene sheets. Nano. Lett. 2008, 8, 2458-2462. [CrossRef] [PubMed]

10. Fischbein, M.D.; Drndic', M. Electron beam nanosculpting of suspended graphene sheets. Appl. Phys. Lett. 2008, $93,113107$. [CrossRef]

11. Hu, W.; Wu, X.; Li, Z.; Yang, J. Helium separation via porous silicene based ultimate membrane. Nanoscale 2013, 5, 90629066. [CrossRef]

12. Kedi, Y.; Shengxi, H.; Xiaofei, C.; Xinwei, W.; Jing, K.; Yan, C.; Jianming, X. Generating Sub-nanometer Pores in Single-Layer MoS 2 by Heavy-Ion Bombardment for Gas Separation: A Theoretical Perspective. ACS Appl. Mater. Interfaces 2018, 10, $28909-28917$.

13. Li, F.; Qu, Y.; Zhao, M. Efficient helium separation of graphitic carbon nitride membrane. Carbon 2015, 95, 51-57. [CrossRef]

14. Wang, Y.; Li, J.; Yang, Q.; Zhong, C. Two-Dimensional Covalent Triazine Framework Membrane for Helium Separation and Hydrogen Purification. ACS Appl. Mater. Interfaces 2016, 8, 8694-8701. [CrossRef]

15. Liu, X.; Chang, X.; Zhu, L.; Li, X. High-efficiency helium separation through $\mathrm{g}-\mathrm{C}_{2} \mathrm{O}$ membrane: A theoretical study. Comput. Mater. Sci. 2019, 157, 1-5. [CrossRef]

16. Zhu, L.; Xue, Q.Z.; Li, X.F.; Wu, T.T.; Jin, Y.K.; Xing, W. $\mathrm{C}_{2} \mathrm{~N}$ : An excellent two-dimensional monolayer membrane for He separation. J. Mater. Chem. 2015, 3, 21351-21356. [CrossRef]

17. Wang, L.; Li, F.; Wang, J.; Li, Y.; Li, W.; Yang, Y.; Zhao, M.; Qu, Y. High-efficiency helium separation through an inorganic graphenylene membrane: A theoretical study. Phys. Chem. Chem. Phys. 2020, 22, 9789-9795. [CrossRef]

18. Rezaee, P.; Naeij, H.R. Graphenylenee1 membrane: An excellent candidate for hydrogen purification and helium separation. Carbon 2020, 157, 779-787. [CrossRef]

19. Meek, S.T.; Greathouse, J.A.; Allendorf, M.D. Metal-organic frameworks: A rapidly growing class of versatile nanoporous materials. Adv. Mater. 2001, 23, 249. [CrossRef] [PubMed]

20. Eddaoudi, M.; Li, H.; Yaghi, O. Highly porous and stable metal-organic frameworks: Structure design and sorption properties. J. Am. Chem. Soc. 2000, 122, 1391-1397. [CrossRef]

21. Stock, N.; Biswas, S. Synthesis of metal-organic frameworks (MOFs): Routes to various MOF topologies, morphologies, and composites. Chem. Rev. 2011, 112, 933-969. [CrossRef] [PubMed]

22. Li, J.-R.; Kuppler, R.J.; Zhou, H.-C. Selective Gas Adsorption and Separation in Metal-Organic Frameworks. Chem. Soc. Rev. 2009, 38, 1477-1504. [CrossRef] [PubMed]

23. Li, J.; Sculley, J.; Zhou, H. Metal-organic frameworks for separations. Chem. Rev. 2012, 112, 869-932. [CrossRef]

24. Adil, K.; Belmabkhout, Y.; Pillai, R.S.; Cadiau, A.; Bhatt, P.M.; Assen, A.H.; Maurin, G.; Eddaoudi, M. Gas/Vapour Separation Using Ultra-Microporous Metal-Organic Frameworks: Insights into the Structure/Separation Relationship. Chem. Soc. Rev. 2017, 46, 3402-3430. [CrossRef]

25. Basdogan, Y.; Keskin, S. Simulation and modelling of MOFs for hydrogen storage. CrystEngComm 2015, 17, 261-275. [CrossRef]

26. Murray, L.J.; Dinca, M.; Long, J.R. Hydrogen storage in metal-organic frameworks. Chem. Soc. Rev. 2009, 38, 1294-1314. [CrossRef]

27. Horcajada, P.; Serre, C.; Maurin, G.; Ramsahye, N.A.; Balas, F.; Vallet-Regi, M.; Sebban, M.; Taulelle, F.; Ferey, G. Flexible porous metal-organic frameworks for a controlled drug delivery. J. Am. Chem. Soc. 2008, 130, 6774-6780. [CrossRef] [PubMed]

28. Zhu, L.; Liu, X.-Q.; Jiang, H.-L.; Sun, L.-B. Metal-Organic Frameworks for Heterogeneous Basic Catalysis. Chem. Rev. 2017, 117, 8129-8176. [CrossRef]

29. Ranjan, R.; Tsapatsis, M. Microporous metal organic framework membrane on porous support using the seeded growth method. Chem. Mater. 2009, 21, 4920-4924. [CrossRef]

30. Cao, F.; Zhang, C.; Xiao, Y.; Huang, H.; Zhang, W.; Liu, D.; Zhong, C.; Yang, Q.; Yang, Z.; Lu, X. Helium recovery by a Cu-BTC metal-organic-framework membrane. Ind. Eng. Chem. Res. 2012, 51, 11274-11278. [CrossRef]

31. Kasik, A.; Dong, X.; Lin, Y. Synthesis and stability of zeolitic imidazolate framework 68 membranes. Micropor. Mesopor. Mater. 2015, 204, 99-105. [CrossRef] 
32. Dong, R.; Zhang, Z.; Tranca, D.C.; Zhou, S.; Wang, M.; Adler, P.; Liao, Z.; Liu, F.; Sun, Y.; Shi, W.; et al. A coronene-based semiconducting two-dimensional metal-organic framework with ferromagnetic behavior. Nat. Commun. 2018, 9, 2637. [CrossRef] [PubMed]

33. Wang, J.; Wang, J.; Song, X.; Qi, S.; Zhao, M. Multifunctional electrocatalytic activity of coronene-based two-dimensional metal-organic frameworks: TM-PTC. Appl. Surf. Sci. 2020, 511, 145393. [CrossRef]

34. Kresse, G.; Furthmuller, J. Efficiency of ab-initio total energy calculations for metals and semiconductors using a plane-wave basis set. Comput. Mater. Sci. 1996, 6, 15-50. [CrossRef]

35. Kresse, G.; Furthmuller, J. Efficient iterative schemes for ab initio total-energy calculations using a plane-wave basis set. Phys. Rev. B 1996, 54, 11169-11186. [CrossRef] [PubMed]

36. Blochl, P.E. Projector augmented-wave method. Phys. Rev. B 1994, 50, 17953-17979. [CrossRef]

37. Perdew, J.P.; Burke, K.; Ernzerhof, M. Generalized gradient approximation made Simple. Phys. Rev. Lett. 1996, 77, 3865-3868. [CrossRef]

38. Grimme, S.; Antony, J.; Ehrlich, S.; Krieg, H. A consistent and accurate ab initio parametrization of density functional dispersion correction (DFT-D) for the 94 elements H-Pu. J. Chem. Phys. 2010, 132, 154104. [CrossRef]

39. Monkhorst, H.J.; Pack, J.D. Special points for Brillouin-zone integrations. Phys. Rev. B 1976, 13, 5188-5192. [CrossRef]

40. Kolsbjerg, E.L.; Groves, M.N.; Hammer, B. An automated nudged elastic band method. J. Chem. Phys 2016, 145, 094107. [CrossRef]

41. Pronk, S.; Pall, S.; Schulz, R.; Larsson, P.; Bjelkmar, P.; Apostolov, R.; Shirts, M.R.; Smith, J.C.; Kasson, P.M.; van der Spoel, D.; et al. GROMACS 4.5: A high-throughput and highly parallel opensource molecular simulation toolkit. Bioinformatics 2013, 29, 845-854. [CrossRef]

42. Garberoglio, G.; Comput, J. OBGMX: A web-based generator of GROMACS topologies for molecular and periodic systems using the universal force field. J. Comput. Chem. 2012, 33, 2204-2208. [CrossRef]

43. Harris, J.G.; Yung, K.H. Carbon Dioxides Liquid-Vapor Coexistence Curve And Critical Properties As Predicted By A Simple Molecular-Model. J. Phys. Chem. 1995, 99, 12021-12024. [CrossRef]

44. Qu, Y.; Li, F.; Zhao, M. Theoretical Design of Highly Efficient $\mathrm{CO}_{2} / \mathrm{N}_{2}$ Separation Membranes Based on Electric Quadrupole Distinction. J. Phys. Chem. C 2017, 121, 17925-17931. [CrossRef]

45. Frisch, M.J.; Trucks, G.W.; Schlegel, H.B.; Scuseria, G.E.; Robb, M.A.; Cheeseman, J.R.; Scalmani, G.; Barone, V.; Petersson, G.A.; Nakatsuji, H.; et al. Gaussian 09, Revision A02. Gaussian. Inc. Wallingford. CT 2009, 7. [CrossRef]

46. Torrie, G.M.; Valleau, J.P. Nonphysical sampling distributions in Monte Carlo free-energy estimation: Umbrella sampling. J. Comput. Phys. 1977, 23, 187-199. [CrossRef]

47. Kumar, S.; Rosenberg, J.M.; Bouzida, D.; Swendsen, R.H.; Kollman, P.A. The weighted histogram analysis method for free-energy calculations on biomolecules.1. The method. J. Comput. Chem. 1992, 13, 1011-1021. [CrossRef]

48. Li, X.; Guo, T.; Zhu, L.; Ling, C.; Xue, Q.; Xing, W. Charge-modulated $\mathrm{CO}_{2}$ capture of $\mathrm{C}_{3} \mathrm{~N}$ nanosheet: Insights from DFT calculations. Chem. Eng. J. 2018, 338, 92-98. [CrossRef]

49. Adewole, J.K.; Ahmad, A.L.; Ismail, S.; Leo, C.P. Current challenges in membrane separation of CO2 from natural gas: A review. Int. J. Greenh. Gas. Control 2013, 17, 46-65. [CrossRef]

50. Chang, X.; Xue, Q.; He, D.; Zhu, L.; Li, X.; Tao, B. 585 divacancy-defective germanene as a hydrogen separation membrane: A DFT study. Int. J. Hydrog. Energy 2017, 42, 24189-24196. [CrossRef]

51. Arrhenius, S. Über die Reaktionsgeschwindigkeit bei der inversion von Rohrzucker durch Sauren. Phys. Chem. 1889, 4, 226-248.

52. Blankenburg, S.; Bieri, M.; Fasel, R.; Müllen, K.; Pignedoli, C.A.; Passerone, D. Porous graphene as an atmospheric nanofilter. Small 2010, 6, 2266-2271. [CrossRef]

53. Zhang, Y.; Shi, Q.; Liu, Y.; Wang, Y.; Meng, Z.; Xiao, C.; Deng, K.; Rao, D.; Lu, R. Hexagonal Boron Nitride with Designed Nanopores as a High-Efficiency Membrane for Separating Gaseous Hydrogen from Methane. J. Phys. Chem. C 2015, 119, 19826-19831. [CrossRef]

54. Sullivan, D.M.; Bruening, M.L. Ultrathin, Gas-Selective Polyimide Membranes Prepared from Multilayer Polyelectrolyte Films. Chem. Mater. 2003, 15, 281-287. [CrossRef]

55. Xu, J.; Zhou, S.; Sang, P.; Li, J.; Zhao, L. Inorganic graphenylene as a promising novel boron nitrogen membrane for hydrogen purification: A computational study. J. Mater. Sci. 2017, 52, 10285-10293. [CrossRef]

56. Zhu, Z. Permeance should be used to characterize the productivity of a polymeric gas separation membrane. J. Membr. Sci. 2006, 281, 754-756. [CrossRef]

57. Wei, S.; Zhou, S.; Wu, Z.; Wang, M.; Wang, Z.; Guo, W.; Lu, X. Mechanistic insights into porous graphene membranes for helium separation and hydrogen purification. Appl. Surf. Sci. 2018, 441, 631-638. [CrossRef] 